University of Nebraska - Lincoln

DigitalCommons@University of Nebraska - Lincoln

\title{
A p38 $\alpha$-Selective Chemosensor for use in Unfractionated Cell Lysates
}

Cliff I. Stains

University of Nebraska-Lincoln, cstains2@unl.edu

Elvedin Luković

Massachusetts Institute of Technology

Barbara Imperiali

Massachusetts Institute of Technology, imper@mit.edu

Follow this and additional works at: https://digitalcommons.unl.edu/chemistrystains

Part of the Chemistry Commons

Stains, Cliff I.; Luković, Elvedin; and Imperiali, Barbara, "A p38 $\alpha$-Selective Chemosensor for use in Unfractionated Cell Lysates" (2011). Cliff Stains Publications. 4.

https://digitalcommons.unl.edu/chemistrystains/4

This Article is brought to you for free and open access by the Published Research - Department of Chemistry at DigitalCommons@University of Nebraska - Lincoln. It has been accepted for inclusion in Cliff Stains Publications by an authorized administrator of DigitalCommons@University of Nebraska - Lincoln. 


\title{
A p38a-Selective Chemosensor for use in Unfractionated Cell Lysates
}

\author{
Cliff I. Stains, Elvedin Luković, and Barbara Imperiali \\ Departments of Chemistry and Biology, Massachusetts Institute of Technology, \\ 77 Massachusetts Avenue, Cambridge, Massachusetts 02139, USA
}

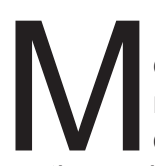
ethods for assessing kinase activities have relied on the transfer of a radioactive $\mathrm{Y}$-phosphoryl moiety from ATP to substrate and have been very useful for in vitro studies of kinases. However, beyond being discontinuous, this assay is incompatible with unfractionated cell lysates since ATP is a common substrate for most kinases. This has prompted the development of protein-based fluorescence resonance energy transfer (FRET) sensors for probing kinase activity (1-3). While useful, these FRET-based sensors produce modest changes in fluorescence upon phosphorylation. Alternatively, the development of methods based on small organic fluorophores has provided sensitive probes for interrogating biological functions $(4,5)$. Recently our laboratory has introduced a direct kinase assay strategy based on chelation-enhanced fluorescence of a cysteine derivative of a sulfonamidooxine fluorophore (6), which we term CSox (Figure 1, panel a). Placed (-)2 or $(+) 2$ relative to the phosphorylation site in an optimized kinase substrate, the CSox amino acid provides a readily observable increase in fluorescence signal in response to phosphorylation due to chelation of $\mathrm{Mg}^{2+}$ between the newly installed phosphoryl group and CSox. These probes afford sensitive real-time fluorescence readouts of kinase activity in unfractionated cell lysates $(7,8)$, provided that selective substrate sequences for the kinase of interest can be identified $(5,9,10)$.

Recently $p 38 \alpha$, a member of the mitogen-activated protein kinase
(MAPK) family, has been the target of a variety of drug development efforts $(11,12)$ since inhibitors of this kinase may provide treatments for inflammatory diseases (13). Additionally, increased activation of p38a in tumor tissue derived from patients with nonsmall cell lung carcinoma has been observed $(14,15)$. Consequently, with the goal of developing a direct p38a chemosensor that would be compatible with unfractionated cell lysates, we investigated strategies for generating selective substrates for MAPKs.

In the case of MAPKs the development of selective probes has proved more challenging due to the minimal local consensus phosphorylation sequence, S/T-P. This class of enzymes (including the ERK, JNK, and p38 family members) derives specificity through the use of extended protein or peptide docking domains that are distal to the phosphorylation site $(16,17)$. These docking domains serve to target a substrate to a particular kinase and can therefore be viewed as unique address elements. Due to the limited structural information concerning p38a substrates, we chose to employ a strategy in which a known docking peptide sequence $(18,19)$ (Figure 1, panel b) would be linked to a CSox-based phosphorylation site via a flexible linker (16) (Figure 1, panel c). Initial phosphorylation reactions indicated that this sensor, MEF2A-CSox, could act as a substrate for purified p38a (Supplementary Figure S1). Phosphorylation reactions containing differing amounts of MEF2A-CSox demonstrated a $K_{M}$ and $V_{\max }$ for $p 38 \alpha$ of $1.3 \mu \mathrm{M}$ and 1.1 $\mu \mathrm{mol} \mathrm{mg} \mathrm{min}^{-1}$, respectively

\begin{abstract}
Recent efforts have identified the p38a Ser/Thr kinase as a potential target for the treatment of inflammatory diseases as well as non-small cell lung carcinoma. Despite the significance of $p 38 \alpha$, no direct activity probe compatible with cell lysate analysis exists. Instead, proxies for kinase activation, such as phosphospecific antibodies, which do not distinguish between p38 isoforms, are often used. Our laboratory has recently developed a sulfonamido-oxine (Sox) fluorophore that undergoes a significant increase in fluorescence in response to phosphorylation at a proximal residue, allowing for real-time activity measurements. Herein we report the rational design of a p38a-selective chemosensor using this approach. We have validated the selectivity of this sensor using specific inhibitors and immunodepletions and show that $p 38 \alpha$ activity can be monitored in crude lysates from a variety of cell lines, allowing for the potential use of this sensor in both clinical and basic science research applications.
\end{abstract}

Corresponding author - B. Imperiali, email imper@mit.edu

Submitted May 17, 2010; accepted and published online September 16, 2010. 
(Figure 2, panel a). We then assessed the specificity of MEF2A-CSox by exposing it to a panel of related kinases (Figure 2, panel b). MEF2A-CSox was selectively phosphorylated by $\mathrm{p} 38 \alpha$ and showed minimal background activity in the presence of the closely related p38 $\beta$ isoform ( $8 \%$ ) and the remaining kinase panel. Importantly, this difference in selectivity for $p 38 \alpha$ over p38 $\beta$ translated into a 17 -fold enhancement in catalytic efficiency for p38a (Supplementary Figure S2). Encouraged by these in vitro studies, we investigated the ability of MEF2ACSox to report $p 38 \alpha$ activation in unfractionated cell lysates.

Several studies have demonstrated p38 $\alpha$ activation in response to inflammatory cytokines or cellular stress (20). With this in mind, we treated HeLa cells with increasing amounts of the cytokine TNFa (Supplementary Figure S3). These initial experiments demonstrated that MEF2A-CSox was capable of reporting p38a activation despite appreciable signal due to phosphorylation by off-target kinases. A recent survey of kinase inhibitors (21) indicated that the broad spectrum inhibitor staurosporine is not effective against $p 38 \alpha$, which was confirmed using recombinant enzyme (Supplementary Figure S4). Consequently we hypothesized that, in this case, staurosporine may be used to reduce the off-target kinase activities allowing for discrimination of the p38a signal. Indeed, the addition of $1 \mu \mathrm{M}$ staurosporine to assays using sorbitol-stimulated lysates demonstrated that a portion of off-target kinases could be suppressed by using this promiscuous inhibitor (Figure 3, panel a), and therefore staurosporine was added to all subsequent lysate assays. A comparison between TNFa and sorbitol stimulation indicated an increase of $68 \%$ in the rate of MEF2A-CSox phosphorylation in cells stimulated by osmotic shock (Figure 3 , panel b), and consequently these lysates were used to optimize assay conditions. Optimal signal-to-noise for sorbitol-stimulated lysates was obtained using $10 \mu \mathrm{g}$ of total protein (Supplementary Figure S5), which provided a clearly discernible enhancement in the rate of phosphorylation of MEF2A-CSox (Figure 3, panel c). Using small molecule inhibitors of $p 38 \alpha$, specifically SB203580, which is
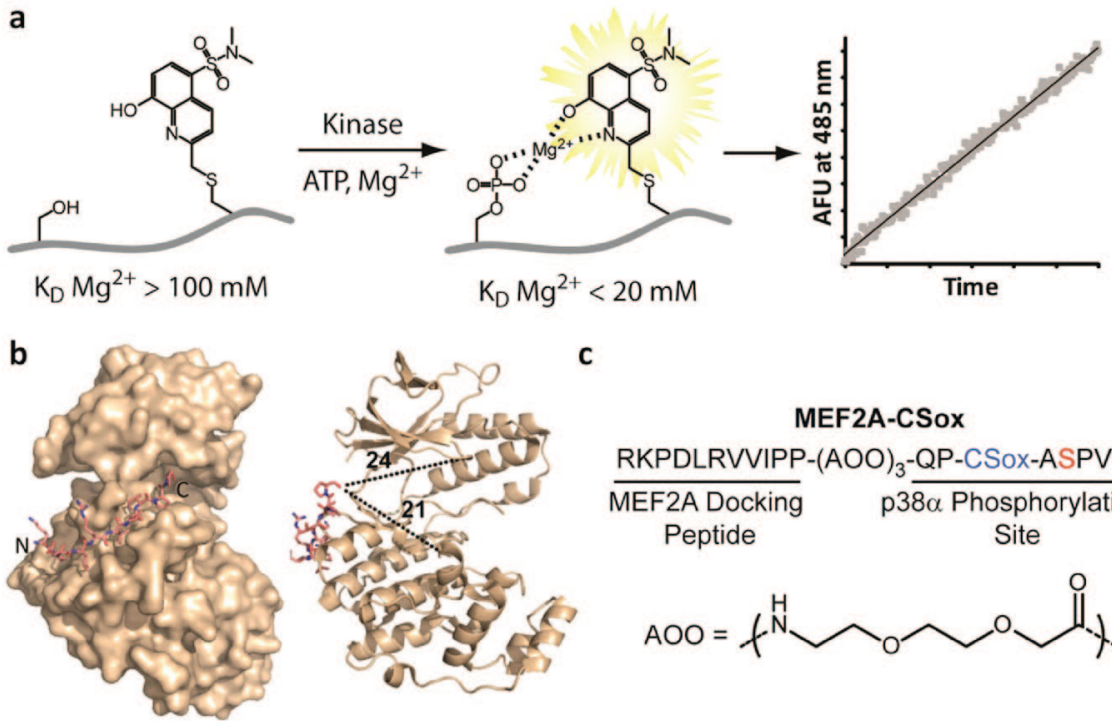

C

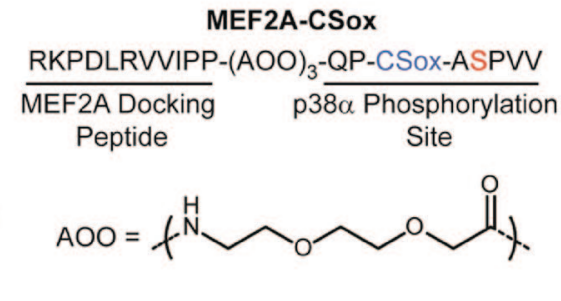

Figure 1. Rational design of a p38a chemosensor. a) A schematic of the chelation-enhanced fluorescence of the CSox amino acid upon phosphorylation. b) Crystal structure of the MEF2A docking peptide bound to p38a (left) and distances in $\AA$ from the C-terminus of the docking peptide to representative distal regions of the catalytic and substratebinding domains of the kinase (right) (18). c) Amino acid sequence of the MEF2A-CSox sensor with the position of CSox (blue) and the site of phosphorylation (red) indicated. The flexible 8-amino-3,6-dioxaoctanoic acid (AOO) linker is also shown.
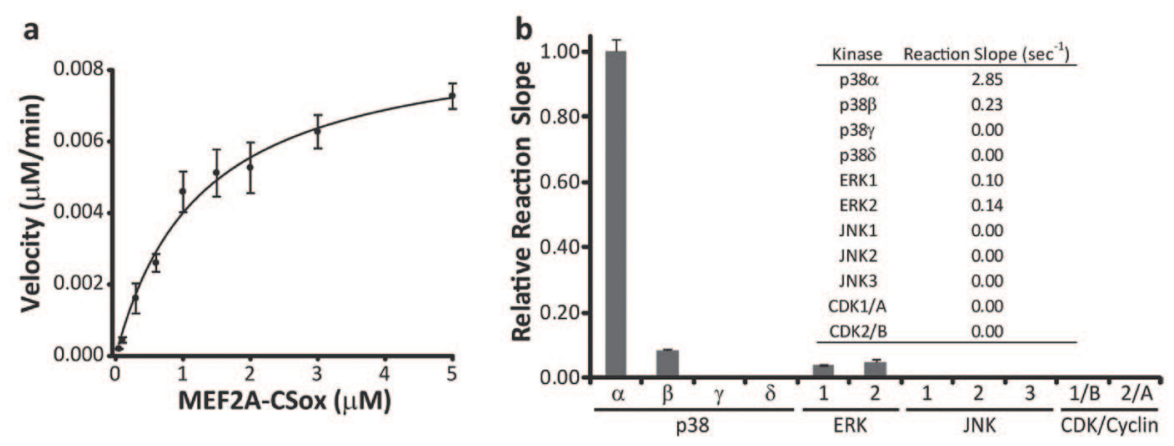

Figure 2. MEF2A-CSox is a substrate for recombinant p38a. a) Direct fit of a velocity versus MEF2A-CSox concentration plot using the Briggs-Haldane equation. b) Phosphorylation reactions were conducted with the indicated recombinant kinase (15 nM) using 1 $\mu \mathrm{M}$ substrate and demonstrate that MEF2A-CSox is selective for p38 $\alpha$ among these kinases. The inset shows the average reaction slope for each kinase.

ATP competitive (22-24), and BIRB796, a slow-binding allosteric inhibitor (25), the origin of the increase in the rate of MEF2A-CSox phosphorylation upon osmotic shock was investigated. The addition of $1 \mu \mathrm{M}$ of each of these compounds, which completely abolishes activity of recombinant kinase (Supplementary Figure S6), reduced the rate of phosphorylation of MEF2A-CSox in sorbitol-stimulated
HeLa lysates to levels observed for serum starved cells (Figure 3, panel d). Appropriate control measurements established that this effect was not due to the inhibitor solvent (DMSO) (Supplementary Figure S7).

We sought to further verify the selectivity of MEF2A-CSox for p38a through a series of inhibition studies, immunodepletion experiments, and analyses across different cell lines 

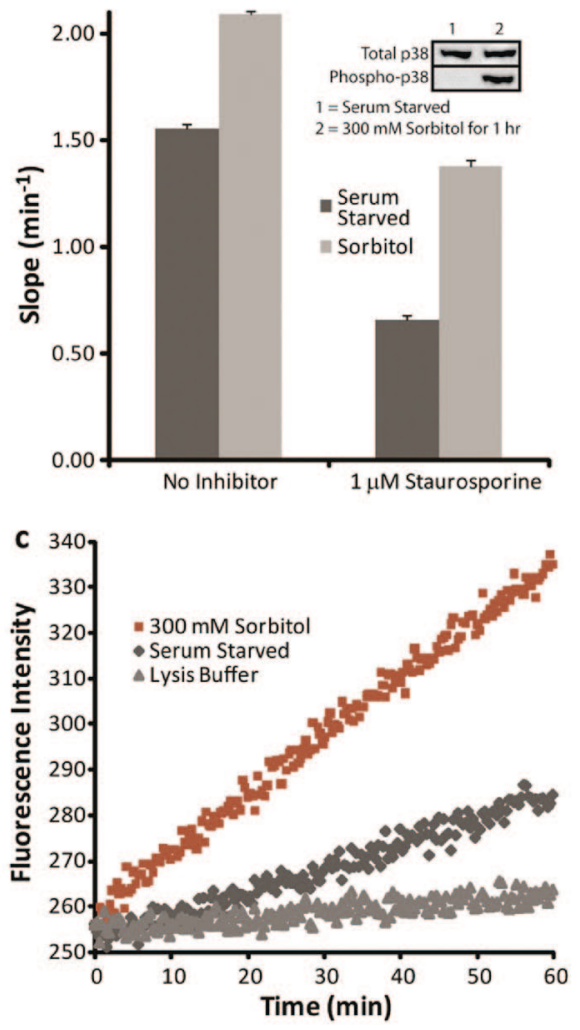
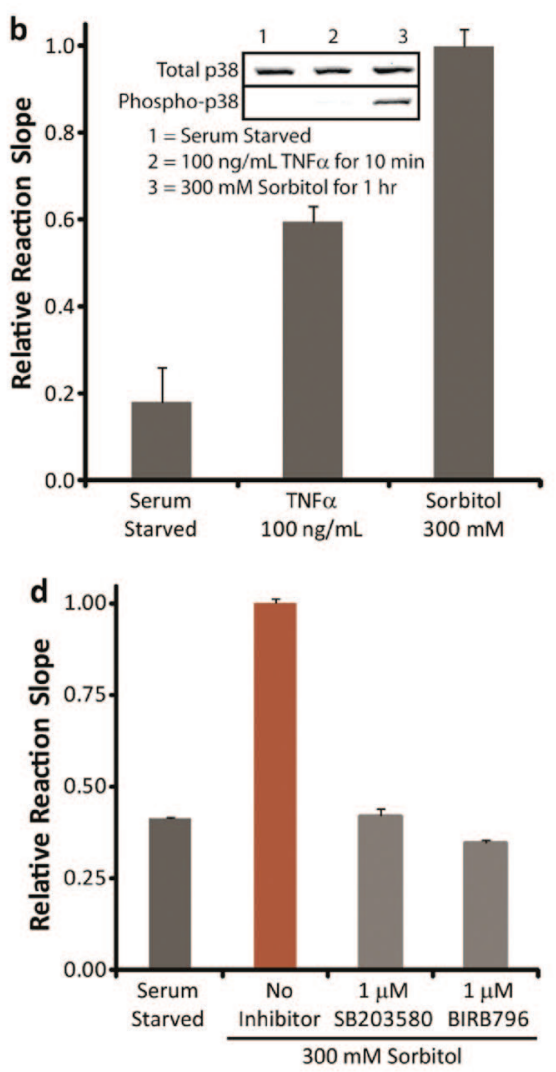

Figure 3. Reducing off-target phosphorylation of MEF2A-CSox in unfractionated cell lysates. a) Reactions were conducted using $1 \mu \mathrm{M}$ substrate and $10 \mu \mathrm{g}$ of the indicated HeLa lysate with or without the addition of staurosporine. The inset shows a Western blot analysis of the indicated lysates, demonstrating p38 activation upon stimulation. b) Relative reaction slopes obtained using $1 \mu \mathrm{M}$ substrate and $5 \mu \mathrm{g}$ of the indicated lysates. The inset shows a Western blot analysis of each lysate. c) Initial phosphorylation reactions using $10 \mu \mathrm{g}$ of total cellular protein from the indicated HeLa cell lysate demonstrated that MEF2A-CSox $(1 \mu \mathrm{M})$ could report on the presence of active p38. Data is corrected for lag times. d) Assays were performed using lysates from serum-starved or stimulated cells $(10 \mu \mathrm{g})$ with MEF2A-CSox $(1 \mu \mathrm{M})$. Inhibitors of $\mathrm{p} 38 \alpha$ were added to the reactions containing lysates from stimulated cells where indicated. All reactions contained $1 \mu \mathrm{M}$ staurosporine unless otherwise noted.

Accordingly, the phosphorylation of MEF2A-CSox was determined in the presence of varying concentrations of SB203580 and BIRB796 (Figure 4, panels $a$ and $b$, respectively). A concentration-dependent decrease in the rate of phosphorylation of MEF2ACSox was observed in the presence of SB203580, yielding a $K_{\mathrm{i}}$ of $7.5 \mathrm{nM}$, which reflects the reported $K_{\mathrm{i}}$ of 21 $\mathrm{nM}$ (24). A similar dose-dependent response was observed for BIRB796 that was in good correlation with previously reported values (25). Importantly, these experiments indicate that the remaining background activity due to off-target kinases could be essentially eliminated through background subtraction of parallel reactions containing $1 \mu \mathrm{M}$ SB203580 (see also Figure 3, panel d). Accordingly, to further verify the specificity of MEF2ACSox, p38a immunodepletion studies were performed in which the activity remaining after the addition of SB203580 was used for background subtraction. These depletions clearly demonstrate that the increase in the rate of phosphorylation of MEF2ACSox upon stimulation by osmotic shock is predominantly due to p38a (Figure 4, panel c). Moreover, similar depletions for the related kinase ERK5 (26) demonstrated no appreciable loss of signal (Supplementary Figure S8). In combination with the known selectivity profiles for the inhibitors used herein (21) (Supplementary Table S1), these results indicate that MEF2A-

CSox is a p38a-selective activity probe and that off-target signal can be virtually eliminated using SB203580.

Finally, we investigated the ability of MEF2A-CSox to report the activation of $p 38 \alpha$ in a variety of cell lines isolated from different tissues and species. Indeed MEF2A-CSox was capable of reporting the activation of $p 38 \alpha$ in HeLa (human), Cos7 (simian), and $\mathrm{NIH}-3 \mathrm{~T} 3$ (rodent) cells (Figure 4, panel d). The activity in each lysate correlated with Western blot analyses indicating that MEF2A-CSox can be used in a variety of mammalian systems and tissues to directly interrogate $p 38 \alpha$ activity levels.

We have designed and validated the first isoform-selective p38 activity probe compatible with unfractionated cell lysates. This probe provides isoform-specific activity information that cannot be obtained through the use of currently available phosphospecific antibodies. Because the synthesis described herein produces $2.4 \mathrm{mg}$ of MEF2A-CSox, sufficient material for 7,000 assays in 96-well plate format or 28,000 assays in 384-well format (7), this sensor could easily be utilized to rapidly screen compound libraries to identify p38 $\alpha$ inhibitors. Furthermore, we envision that this sensor will be useful for detailing the changes in kinase signaling pathways during cellular transformations such as differentiation and cancer development (15).

\section{Methods}

General Reagents and Methods. Low metals grade chemicals were obtained from Sigma and Alfa Aesar. Lysates were normalized for total protein content using the Bio-Rad protein assay (500-0006) with BSA as a standard. Fluorescence emission was acquired at $485 \mathrm{~nm}$ using $360 \mathrm{~nm}$ excitation on either a HTS 7000 Bio Assay Reader (Perkin-Elmer) or Spectramax Gemini XS (Molecular Devices, $455 \mathrm{~nm}$ cutoff) plate reader. All fluorescence assays were performed at $30^{\circ} \mathrm{C}$ in 96 -well plates (Corning, 3992).

Synthesis of MEF2A-Csox. MEF2ACSox was synthesized using standard Fmoc-based solid-phase peptide synthesis methods as described previously (6). The linker in MEF2A-CSox was installed by coupling three Fmoc-protected $\mathrm{AOO}$ linkers (Novabiochem, 851037) to the growing peptide chain on $100 \mathrm{mg}$ of PAL-PEG-PS resin $\left(0.19 \mathrm{mmol} \mathrm{g}^{-1}\right.$ substitution, Applied Biosystems). The Sox fluorophore was 

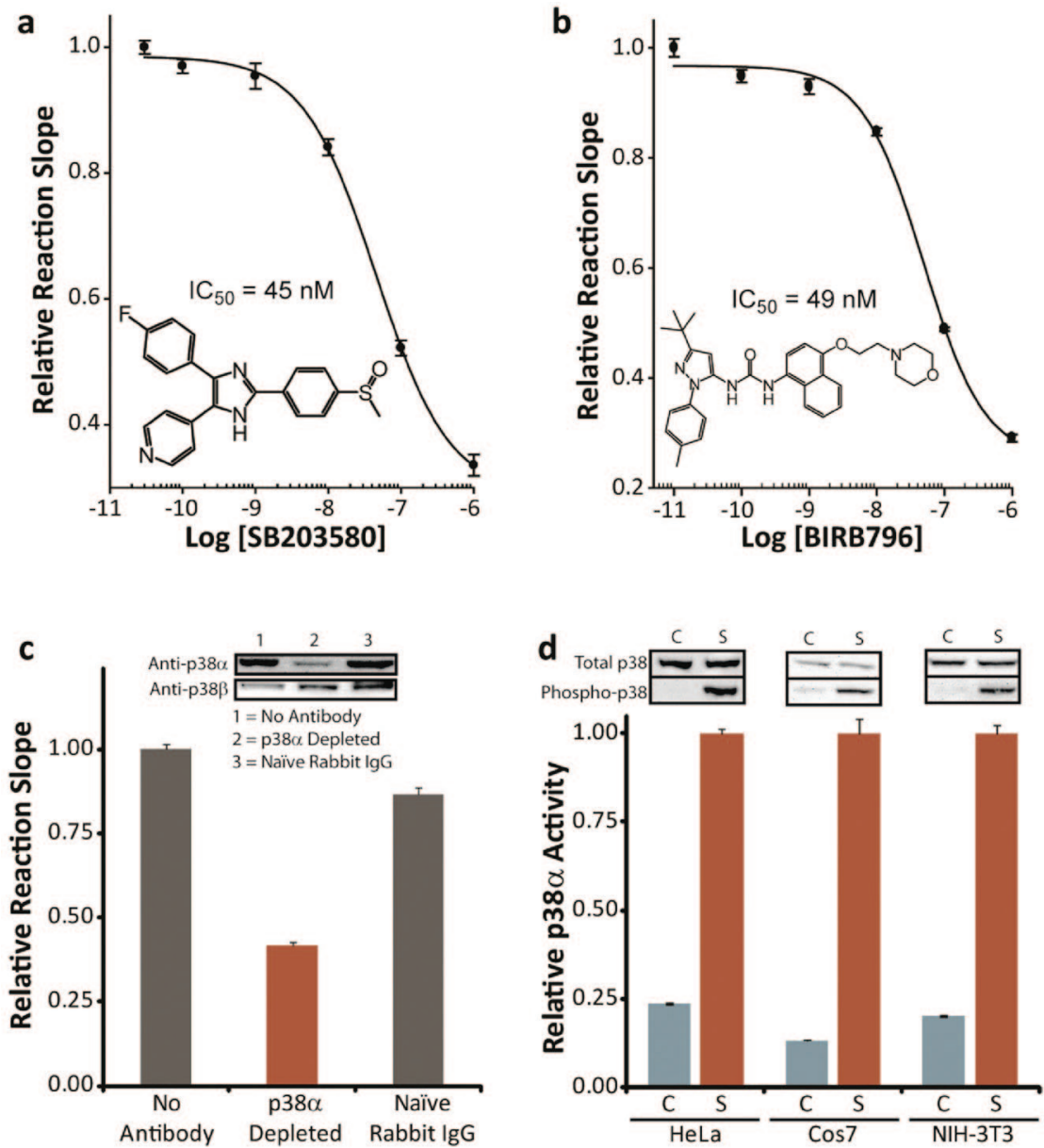

Figure 4. MEF2A-CSox can selectively report on p38 $\alpha$ activation in unfractionated cell lysates. Dose-dependent responses to the addition of SB203580 (a) and BIRB796 (b) were observed in sorbitol-stimulated lysates $(10 \mu \mathrm{g})$ using MEF2A-CSox $(1 \mu \mathrm{M})$. The observed $\mathrm{IC}_{50}$ and structure of each compound are shown in the inset. c) Phosphorylation reactions were performed on lysates that had been depleted using a p38a-specific antibody. Values were background subtracted using the activity remaining in the input lysate after addition of $1 \mu \mathrm{M}$ SB203580. The inset shows a Western blot of the immunodepleted lysates. d) The indicated cell lines were stimulated with $300 \mathrm{mM}$ sorbitol for $1 \mathrm{~h}$ (S). Phosphorylation reactions were performed as above and compared to lysates from cells that had not been stimulated $(C)$. The amount of p38 $\alpha$ activity in each individual lysate was determined by subtracting the activity remaining after the addition of $1 \mu \mathrm{M}$ SB203580. Western blots for both total and active p38 are shown above each sample. All reactions contained $1 \mu \mathrm{M}$ staurosporine.

incorporated via on-resin alkylation of a selectively deprotected cysteine residue (6). The resulting peptide was acetyl-capped at the $\mathrm{N}$-terminus and included a C-terminal amide derived from the resin. Purification was carried out by standard reverse phase HPLC. Characterization was performed using ESI-MS, and concentrations were determined based on the Sox chromophore using the absorbance of the peptide at $355 \mathrm{~nm}$ in $0.1 \mathrm{M} \mathrm{NaOH}$ containing $1 \mathrm{mM}$ $\mathrm{Na}_{2}$ EDTA (extinction coefficient $=8,427 \mathrm{M}^{-1}$ $\left.\mathrm{cm}^{-1}\right)(27)$

MEF2A-CSox Reactions Containing Recombinant Enzyme. Reactions were carried out using $15 \mathrm{nM}$ of the indicated enzyme (Invitrogen) and $1 \mu \mathrm{M}$ MEF2A-CSox in a buffer containing $50 \mathrm{mM}$ Tris- $\mathrm{HCl}(\mathrm{pH}=$ 7.5 at $25^{\circ} \mathrm{C}$ ), $10 \mathrm{mM} \mathrm{MgCl}, 1 \mathrm{mM}$ EGTA,
$2 \mathrm{mM}$ DTT, $0.01 \%$ Triton X-100, and $1 \mathrm{mM}$ ATP in a final volume of $120 \mu \mathrm{L}$. Well-towell path length variation was corrected by normalizing to starting intensities.

Determination of Kinetic Parameters of MEF2A-CSox with $p 38 \alpha$ and $\beta$. Reactions were performed as above using $1 \mathrm{ng}$ of recombinant human p38 $\alpha$ or $\beta$ (Invitrogen) with increasing concentrations of substrate. Initial reaction slopes were then converted to rates as described previously (27).

Recombinant Kinase Panel Assays. Reactions were conducted as described above with $1 \mu \mathrm{M}$ MEF2A-CSox and $15 \mathrm{nM}$ of the indicated kinase (Invitrogen).

Preparation of Cell Lysates. HeLa cells were propagated in 90\% DMEM supplemented with $10 \%$ heat-inactivated FBS,
$50 \mathrm{U} \mathrm{mL}^{-1}$ penicillin, and $50 \mu \mathrm{g} \mathrm{mL}{ }^{-1}$ streptomycin. Cos7 and NIH-3T3 cells were propagated in $90 \%$ DMEM supplemented with $10 \%$ FBS, $50 \mathrm{U} \mathrm{mL}^{-1}$ penicillin, and $50 \mu \mathrm{g} \mathrm{mL}^{-1}$ streptomycin. Prior to stimulation, cells were starved overnight ( $14 \mathrm{~h}$ ) by the addition of DMEM supplemented with 2 $\mathrm{mM} \mathrm{I-GIn,} 50 \mathrm{U} \mathrm{mL}^{-1}$ penicillin, and $50 \mu \mathrm{g}$ $\mathrm{mL}^{-1}$ streptomycin. Cells were stimulated by the addition of the indicated amount of TNFa (Cell Signaling) for 10 min or sorbitol to $300 \mathrm{mM}$ for $1 \mathrm{~h}$. Cells were then washed with ice-cold PBS and lysed on ice in 50 $\mathrm{mM}$ Tris $\left(\mathrm{pH}=7.5\right.$ at $\left.25^{\circ} \mathrm{C}\right), 150 \mathrm{mM} \mathrm{NaCl}$, $50 \mathrm{mM} \beta$-glycerophosphate, $10 \mathrm{mM}$ sodium pyrophosphate, $30 \mathrm{mM} \mathrm{NaF}, 1 \%$ Triton $\mathrm{X}-100,2 \mathrm{mM}$ EGTA, $100 \mu \mathrm{M} \mathrm{Na}_{3} \mathrm{VO}_{4}, 1 \mathrm{mM}$ DTT, protease inhibitor cocktail III $(10 \mu \mathrm{L}$ $\mathrm{mL}^{-1}$, Calbiochem, 539134), and phosphatase inhibitor cocktail $1\left(10 \mu \mathrm{L} \mathrm{mL}^{-1}\right.$, Sigma, P2825). Lysates were clarified by centrifugation, and supernatants were flash frozen in liquid nitrogen and stored at $-80^{\circ} \mathrm{C}$.

Immunodepletions. Immunodepletions were conducted as described previously (8). Briefly, sorbitol-stimulated HeLa lysates were aliquoted into separate samples $\left(350 \mu \mathrm{g}\right.$ each) at $4{ }^{\circ} \mathrm{C}$. Depletions were conducted using a rabbit anti-p38a $(1 \mu \mathrm{g})$ antibody (Cell Signaling, 9218) along with a naïve rabbit IgG control $(1 \mu \mathrm{g}$, GE Life Sciences). Antibody-bound complexes were precipitated by the addition of Protein $A$ agarose conjugated beads (GE Life Sciences). Input (untreated) samples were used to determined the amount of activity lost due to handling, while a separate sample was treated with Protein A beads alone to determine the amount of activity lost due to nonspecific binding to the resin. Lysates were flash frozen and stored at -80 ${ }^{\circ} \mathrm{C}$. ERK5 depletions were conducted in a similar manner using the appropriate antibody (Cell Signaling, 3372). The rate of phosphorylation by off-target kinases was background-subtracted using the activity remaining after the addition of $1 \mu \mathrm{M}$ SB203580 to the input lysates.

MEF2A-CSox Lysate Assays. Assays were typically conducted using $1 \mu \mathrm{M}$ MEF2A-CSox, $10 \mu \mathrm{g}$ of total protein from cell lysates, and $1 \mu \mathrm{M}$ staurosporine, unless otherwise indicated. Reactions were prepared in bulk in a buffer consisting of 50 $\mathrm{mM}$ Tris- $\mathrm{HCl}\left(\mathrm{pH}=7.5\right.$ at $\left.25^{\circ} \mathrm{C}\right), 10 \mathrm{mM}$ $\mathrm{MgCl}_{2}, 1 \mathrm{mM}$ EGTA, $2 \mathrm{mM} \mathrm{DTT}$, and $0.01 \%$ Brij $35 \mathrm{P}$ with the indicated concentration of p38a inhibitor and aliquoted into 96-well plates. After addition of lysate, reactions (final volume $120 \mu \mathrm{L}$ ) were incubated at 30 ${ }^{\circ} \mathrm{C}$, and fluorescence emission was monitored. Data were corrected for lag times (typically 5-10 min, after which fluorescence increases were linear with respect to time for at least $1 \mathrm{~h}$ ) as well as variations in well-to-well path lengths. For titrations with SB203580, the calculated $\mathrm{IC}_{50}$ was converted to a $K_{\mathrm{i}}$ value using the Cheng-Prussof equation with the concentration of ATP in the assay and the reported $K_{\mathrm{M}}$ of p38 $\alpha$ 
for ATP (24). Slopes for assays containing the slow-binding inhibitor BIRB796 (25) were determined after a 10 min incubation of the entire solution at $30^{\circ} \mathrm{C}$. After this incubation fluorescence increases were linear with respect to time for at least $1 \mathrm{~h}$.

Slopes of phosphorylation reactions for assays containing lysates from different cell lines (Figure 4, panel d) were background corrected using the activity remaining in each individual lysate after the addition of 1 $\mu \mathrm{M}$ SB203580.

Western Blot Analysis. Lysates $(20 \mu \mathrm{g}$ total protein unless noted) were separated by SDS-PAGE, and proteins were transferred to a nitrocellulose membrane. Blots were probed with primary antibodies for total p38 (Cell Signaling, 9212), phospho-p38 (Cell Signaling, 9215), p38a, p38ß (Cell Signaling, 2339), total ERK5 (Cell Signaling, 3372), or phospho-ERK5 (Cell Signaling, $3371,300 \mu \mathrm{g}$ of total protein used for blot), which were detected using an HRP conjugated goat anti-rabbit secondary antibody (Pierce, 32460). Blots were visualized by enhanced chemiluminescence (Pierce, 34075).

Acknowledgments - C.S. was supported by a National Institutes of Health NRSA Fellowship (F32GM085909). This research was supported by a grant from the $\mathrm{NIH}$ (GM064346 - Cell Migration Consortium). We also acknowledge Professor A. Cuenda and Professor K. Dalby for providing a sample of BIRB796 and the Biophysical Instrumentation Facility for the Study of Complex Macromolecular Systems (NSF-0070319).

Supporting Information is presented following the References.

\section{References}

1. Harvey, C. D., Ehrhardt, A. G., Cellurale, C., Zhong, H. N., Yasuda, R., Davis, R. J., and Svoboda, K. (2008) A genetically encoded fluorescent sensor of ERK activity Proc. Natl. Acad. Sci. U.S.A. 105, 19264-19269

2. Kunkel, M. T., Toker, A., Tsien, R. Y., and Newton, A. C. (2007) Calcium-dependent regulation of protein kinase $D$ revealed by a genetically encoded kinase activity reporter J. Biol. Chem. 282, 6733-6742

3. Sato, M., Kawai, Y., and Umezawa, Y. (2007) Genetically encoded fluorescent indicators to visualize protein phosphorylation by extracellular signal-regulated kinase in single living cells Anal. Chem. 79, 2570-2575

4. Lee, H. M., Larson, D. R., and Lawrence, D. S. (2009) Illuminating the chemistry of life: design, synthesis, and applications of "caged" and related photoresponsive compounds ACS Chem. Biol. 4, 409-427

5. Rothman, D. M., Shults, M. D., and Imperiali, B. (2005) Chemical approaches for investigating phosphorylation in sig- nal transduction networks Trends Cell Biol. 15, 502-510

6. Luković, E., Gonzalez-Vera, J. A., and Imperiali, B. (2008) Recognition-domain focused chemosensors: versatile and efficient reporters of protein kinase activity J. Am. Chem. Soc. 130, 12821-12827

7. Luković, E., Vogel Taylor, E., and Imperiali, B. (2009) Monitoring protein kinases in cellular media with highly selective chimeric reporters Angew. Chem., Int Ed. 48, 6828-6831

8. Shults, M. D., Janes, K. A., Lauffenburger, D. A., and Imperiali, B. (2005) A multiplexed homogeneous fluorescence-based assay for protein kinase activity in cell lysates Nat. Methods 2 , 277-283

9. Gonzalez-Vera, J. A., Luković, E., and Imperiali, B. (2009) A rapid method for generation of selective Sox-based chemosensors of Ser/Thr kinases using combinatorial peptide libraries Bioorg. Med. Chem. Lett. 19, 1258-1260

10. Shults, M. D., Carrico-Moniz, D., and Imperiali, B. (2006) Optimal Sox-based fluorescent chemosensor design for serine/threonine protein kinases Anal. Biochem. 352, 198-207

11. Clark, M. A., Acharya, R. A., AricoMuendel, C. C., Belyanskaya, S. L., Benjamin, D. R., Carlson, N. R., Centrella, P. A., Chiu, C. H., Creaser, S. P., Cuozzo, J. W., Davie, C. P., Ding, Y., Franklin, G. J., Franzen, K. D., Gefter, M. L., Hale, S. P., Hansen, N. J. V., Israel, D. I., Jiang, J. W., Kavarana, M. J., Kelley, M. S., Kollmann, C. S., Li, F., Lind, K., Mataruse, S., Medeiros, P. F., Messer, J. A., Myers, P., O'Keefe, H., Oliff, M. C., Rise, C. E., Satz, A. L., Skinner, S. R., Svendsen, J. L., Tang, L. J., van Vloten, K., Wagner, R. W., Yao, G., Zhao, B. G., and Morgan, B. A (2009) Design, synthesis and selection of DNA-encoded small-molecule libraries Nat. Chem. Biol. 5, 647-654

12. Simard, J. R., Kluter, S., Grutter, C., Getlik, M., Rabiller, M., Rode, H. B., and Rauh, D. (2009) A new screening assay for allosteric inhibitors of CSrc Nat. Chem. Biol. 5, 394-396

13. Kumar, S., Boehm, J., and Lee, J. C. (2003) p38 map kinases: Key signalling molecules as therapeutic targets for inflammatory diseases Nat. Rev. Drug Discovery 2, 717-726

14. Greenberg, A. K., Basu, S., Hu, J., Yie, T. A., Tchou-Wong, K. M., Rom, W. N., and Lee, T. C. (2002) Selective p38 activation in human non-small cell lung cancer Am. J. Respir. Cell Mol. Biol. 26, 558-564

15. Wagner, E. F. and Nebreda, A. R. (2009) Signal integration by JNK and p38 MAPK pathways in cancer development Nat. Rev. Cancer 9, 537-549

16. Fernandes, N., Bailey, D. E., Vanvranken, D. L., and Allbritton, N. L. (2007) Use of docking peptides to design modular substrates with high efficiency for mitogen-activated protein kinase extracellular signal-regulated kinase ACS Chem. Biol. 2, 665-673
17. Goldsmith, E. J., Akella, R., Min, X. S., Zhou, T. J., and Humphreys, J. M. (2007) Substrate and docking interactions in serine/threonine protein kinases Chem. Rev. 107, 5065-5081

18. Chang, C. I., Xu, B. E., Akella, R., Cobb, M. H., and Goldsmith, E. J. (2002) Crystal structures of MAP kinase p38 complexed to the docking sites on its nuclear substrate MEF2A and activator MKK3b Mol. Cell 9, 1241-1249

19. Barsyte-Lovejoy, D., Galanis, A., and Sharrocks, A. D. (2002) Specificity determinants in MAPK signaling to transcription factors J. Biol. Chem. 277, 9896-9903

20. Raingeaud, J., Gupta, S., Rogers, J. S., Dickens, M., Han, J., Ulevitch, R. J., and Davis, R. J. (1995) Pro-inflammatory cytokines and environmental stress cause p38 mitogen-activated protein kinase activation by dual phosphorylation on tyrosine and threonine J. Biol. Chem. $270,7420-7426$

21. Karaman, M. W., Herrgard, S., Treiber, D. K., Gallant, P., Atteridge, C. E., Campbell, B. T., Chan, K. W., Ciceri, P., Davis, M. I., Edeen, P. T., Faraoni, R., Floyd, M., Hunt, J. P., Lockhart, D. J., Milanov, Z. V., Morrison, M. J., Pallares, G., Patel, H. K., Pritchard, S., Wodicka, L. M., and Zarrinkar, P. P. (2008) A quantitative analysis of kinase inhibitor selectivity Nat. Biotechnol. 26, 127-132

22. Cuenda, A., Rouse, J., Doza, Y. N., Meier, R., Cohen, P., Gallagher, T. F., Young, P. R., and Lee, J. C. (1995) SB 203580 is a specific inhibitor of a MAP kinase homologue which is stimulated by cellular stresses and interleukin-1 FEBS Lett. 364, 229-233

23. Lee, J. C., Laydon, J. T., McDonnell, P. C., Gallagher, T. F., Kumar, S., Green, D., McNulty, D., Blumenthal, M. J., Heys, J. R., and Landvatter, S. W. 1994, A protein kinase involved in the regulation of inflammatory cytokine biosynthesis Nature 372, 739-746

24. Young, P. R., McLaughlin, M. M., Kumar, S., Kassis, S., Doyle, M. L., McNulty, D., Gallagher, T. F., Fisher, S., McDonnell, P. C., Carr, S. A., Huddleston, M. J., Seibel, G., Porter, T. G., Livi, G. P., Adams, J. L., and Lee, J. C. (1997) Pyridinyl imidazole inhibitors of p38 mitogen-activated protein kinase bind in the ATP site J. Biol. Chem. 272, 12116-12121

25. Pargellis, C., Tong, L., Churchill, L., Cirillo, P. F., Gilmore, T., Graham, A. G., Grob, P. M., Hickey, E. R., Moss, N., Pav, S., and Regan, J. (2002) Inhibition of p38 MAP kinase by utilizing a novel allosteric binding site Nat. Struct. Biol. 9, 268-272

26. Barsyte-Lovejoy, D., Galanis, A., Clancy, A., and Sharrocks, A. D. (2004) ERK5 is targeted to myocyte enhancer factor 2A (MEF2A) through a MAPK docking motif Biochem. J. 381, 693-699

27. Shults, M. D. and Imperiali, B. (2003) Versatile fluorescence probes of protein kinase activity J. Am. Chem. Soc. 125, 14248-14249 
Supplementary Information

\section{A p38 $\alpha$ Selective Chemosensor for use in Unfractionated Cell Lysates}

Cliff I. Stains, Elvedin Luković \& Barbara Imperiali*

Departments of Chemistry and Biology, Massachusetts Institute of Technology, 77 Massachusetts Ave., Cambridge MA 02139

Correspondence should be addressed to B.I. (imper@mit.edu) 


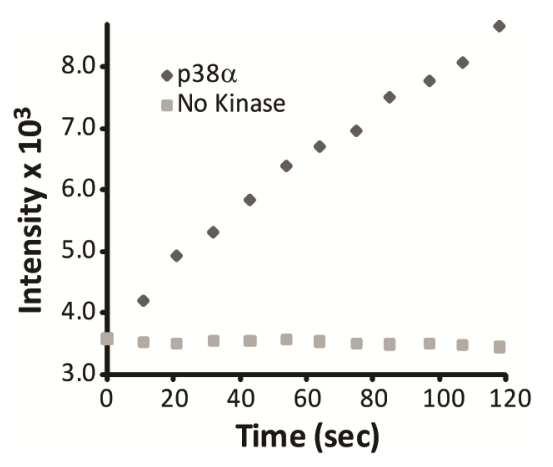

Supplementary Figure S1. MEF2A-CSox is a substrate for p38 $\alpha$. Initial phosphorylation reactions with and without the addition of kinase $(15 \mathrm{nM})$ indicated that MEF2A-CSox $(1 \mu \mathrm{M})$ was a substrate for $p 38 \alpha$. 


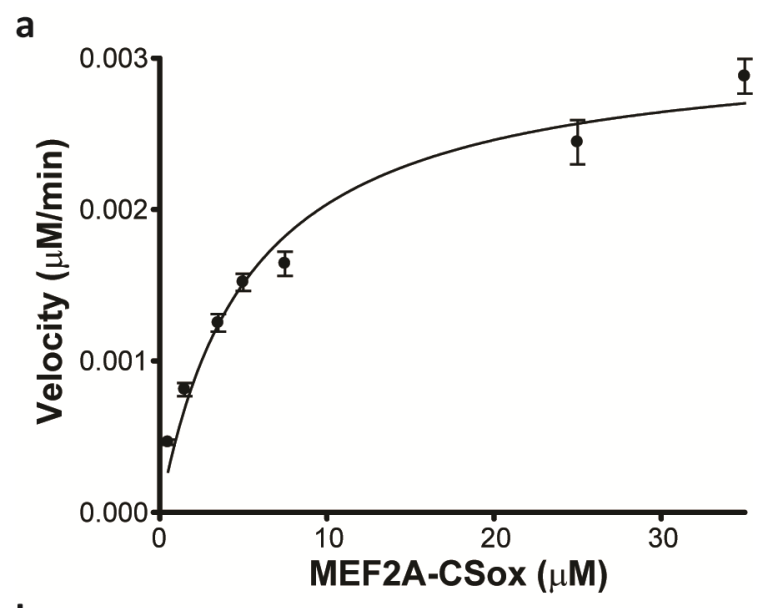

b

\begin{tabular}{cccc} 
Kinase & $\mathrm{K}_{\mathrm{M}}(\mu \mathrm{M})$ & $\mathrm{k}_{\text {cat }}\left(\mathrm{min}^{-1}\right)$ & $\begin{array}{c}\text { Catalytic } \\
\text { Efficiency }\end{array}$ \\
\hline $\mathrm{p} 38 \alpha$ & 1.3 & 74 & 17 \\
$\mathrm{p} 38 \beta$ & 5.3 & 18 & 1.0 \\
\hline
\end{tabular}

Supplementary Figure S2. Kinetic parameters of MEF2A-CSox for p38 $\beta$. a) A direct fit of a velocity versus MEF2A-CSox concentration plot using the Briggs-Haldane equation (1 ng p38 $\beta$ ). b) Kinetic parameters of MEF2A-CSox for the indicated kinases, demonstrating that MEF2ACSox is a more efficient substrate for p38 $\alpha$. Catalytic efficiency was determined using relative $\mathrm{k}_{\text {cat }} / \mathrm{K}_{\mathrm{M}}$ values. 
a

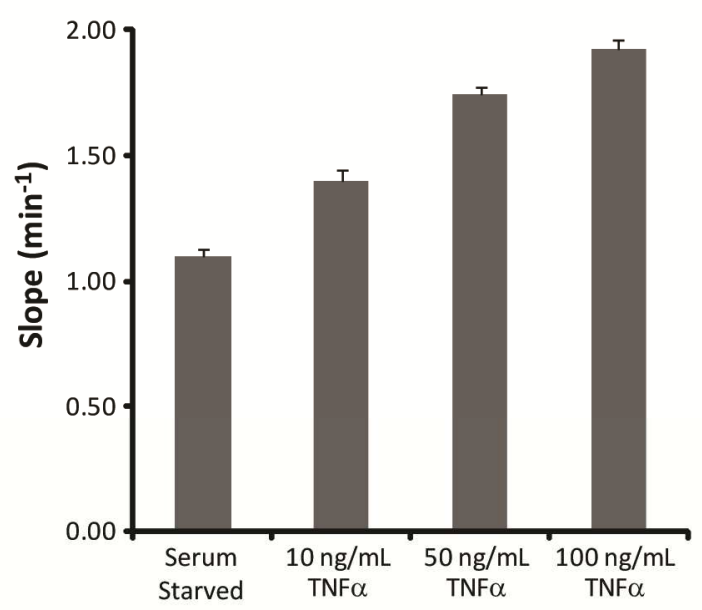

C

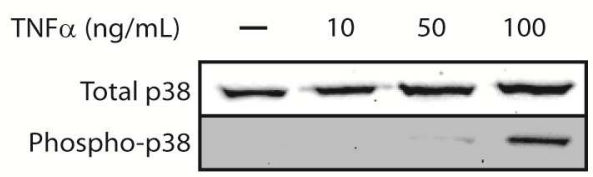

b

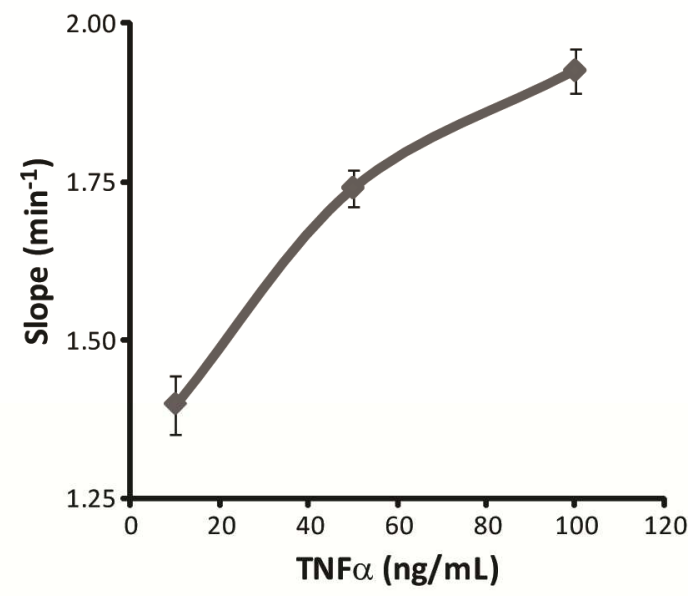

Supplementary Figure S3. MEF2A-CSox phosphorylation varies with TNF $\alpha$ stimulation. a) Fluorescence slopes of reactions conducted without staurosporine using $1 \mu \mathrm{M}$ substrate and 5 $\mu \mathrm{g}$ of HeLa lysates derived from cells stimulated for $10 \mathrm{~min}$ with the indicated amount of TNF $\alpha$. Assays were also performed with lysates from untreated (serum starved) cells. b) The relationship between MEF2A-CSox phosphorylation and the amount of TNF $\alpha$ used for stimulation. c) A western blot of the indicated lysates with the corresponding antibodies, demonstrating increased phosphorylation of p38 with increasing amounts of TNF $\alpha$. 


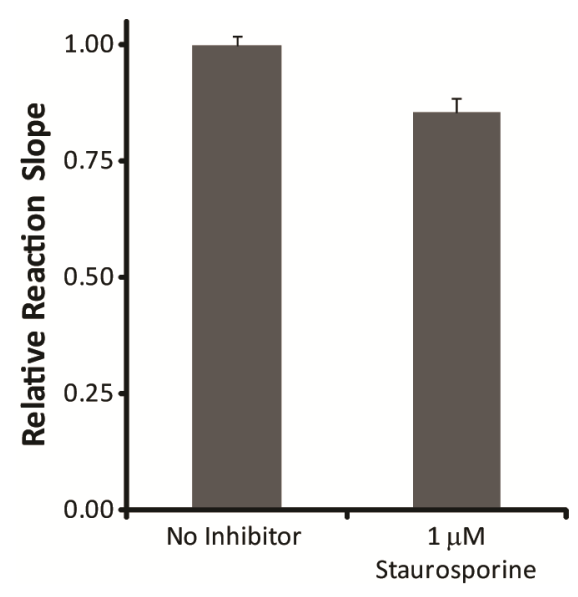

Supplementary Figure S4. Staurosporine does not significantly alter p38 $\alpha$ activity (1). Reactions were performed using $1 \mathrm{nM}$ recombinant $\mathrm{p} 38 \alpha$ and $1 \mu \mathrm{M}$ substrate. 

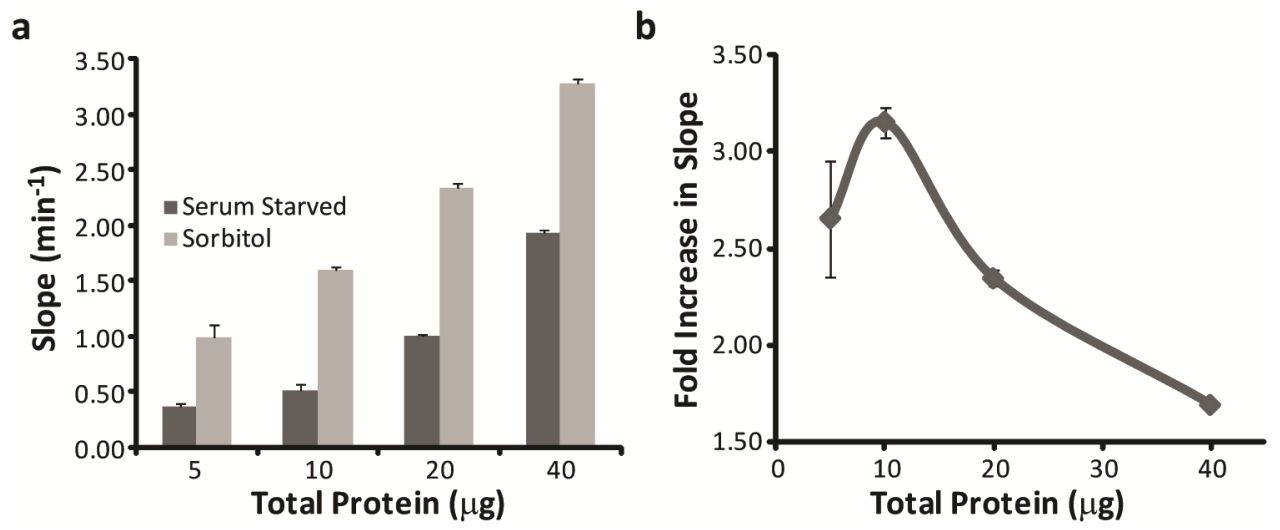

Supplementary Figure S5. The effect of the amount of lysate used in the assay on the rate of phosphorylation of MEF2A-CSox. a) Reactions conducted with $1 \mu \mathrm{M}$ substrate and the indicated amount of serum starved and sorbitol-stimulated HeLa lysates. b) The fold change in reaction slope between sorbitol-stimulated and serum starved lysates with respect to the amount of lysate used in the assay. The assay is most sensitive when $10 \mu \mathrm{g}$ of lysate is used. Presumably the sensitivity of the assay decreases with increasing concentrations of lysate due to the increasing amounts of off-target kinases. All reactions contained $1 \mu \mathrm{M}$ staurosporine. 


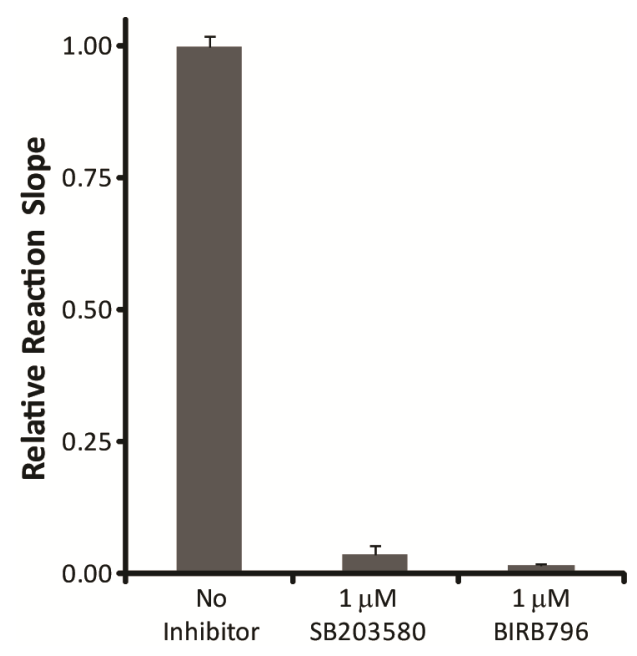

Supplementary Figure S6. The addition of $1 \mu \mathrm{M}$ SB203580 or BIRB796 completely abolishes recombinant $\mathrm{p} 38 \alpha$ activity. Reactions were conducted with $1 \mu \mathrm{M}$ substrate and $1 \mathrm{nM}$ recombinant enzyme. Slopes for assays containing the slow-binding inhibitor BIRB796 were determined after incubation of the entire reaction at $30{ }^{\circ} \mathrm{C}$ for 30 min prior to data collection, after which fluorescence increases were linear with respect to time. 


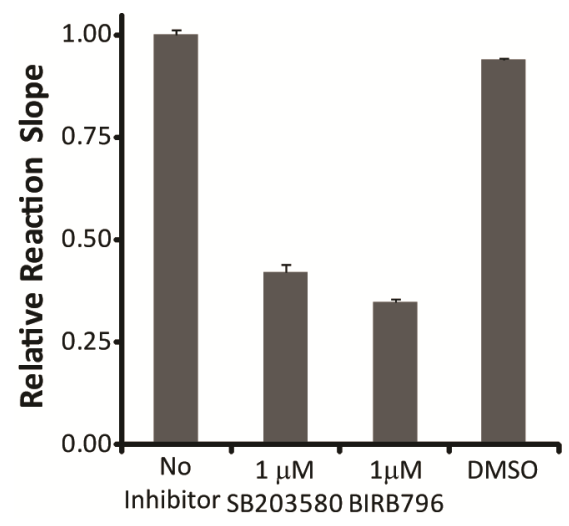

Supplementary Figure S7. The inhibitor solvent, DMSO, does not influence the phosphorylation of MEF2A-CSox. Assays were conducted using $1 \mu \mathrm{M}$ MEF2A-CSox and $10 \mu \mathrm{g}$ of sorbitol-stimulated HeLa lysates with the indicated inhibitor. All reactions contained $1 \mu \mathrm{M}$ staurosporine. 
a

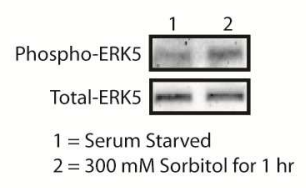

b

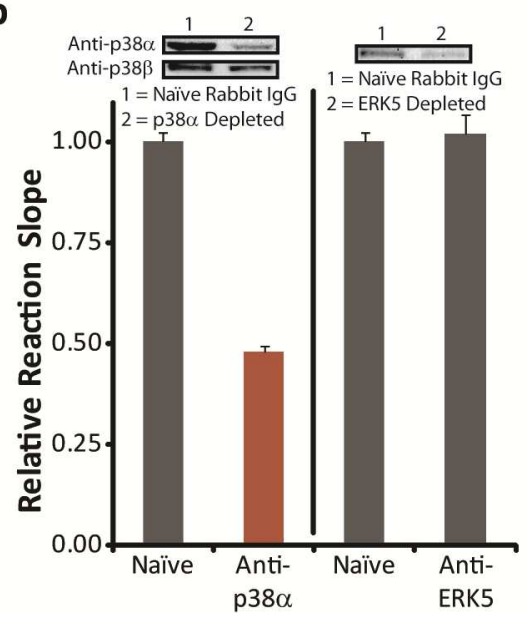

Supplementary Figure S8. The related ERK5 kinase does not significantly contribute to the phosphorylation of MEF2A-CSox $(1 \mu \mathrm{M})$ in sorbitol-stimulated HeLa cell lysates. a) Western blot analysis of sorbitol-stimulated lysates demonstrating activation of ERK5. b) Immunodepletion of p38 $\alpha$ leads to a dramatic decrease in MEF2A-CSox phosphorylation (left) while depletion of ERK5 demonstrated no significant loss of signal (right). Values were background subtracted using the activity remaining in the input lysates after addition of $1 \mu \mathrm{M} \mathrm{SB203580}$. Western blots of the respective lysates demonstrating depletion of the target kinase are shown in the insets of each panel. Note that $p 38 \beta$ levels remain unchanged, indicating that the remaining MEF2ACSox activity is likely due to residual $\mathrm{p} 38 \alpha(\sim 30 \%$ remaining by gel densitometry). All reactions contained $1 \mu \mathrm{M}$ staurosporine. 


\begin{tabular}{cccc} 
& \multicolumn{3}{c}{ Inhibitor } \\
\cline { 2 - 4 } Kinase & SB203580 & BIRB796 & Staurosporine \\
\hline p38 $\alpha$ & 12 & 0.37 & $>10,000$ \\
p38 $\beta$ & 70 & 1,500 & $>10,000$ \\
p38y & 1,500 & 19 & 42 \\
JNK1 & 1,100 & $>10,000$ & 220 \\
JNK2 & 130 & 7.3 & $>10,000$ \\
JNK3 & 35 & 110 & 110 \\
ERK1 & $>10,000$ & $>10,000$ & 8,400 \\
ERK2 & $>10,000$ & $>10,000$ & 7,300 \\
ERK5 & $>10,000$ & $>10,000$ & 1,600 \\
\hline$K_{\text {D in nM }}$ & &
\end{tabular}

Supplementary Table S1. Reported dissociation constants of SB203580, BIRB796, and staurosporine for the indicated kinase are given (1). 


\section{References}

1. Karaman, M. W., Herrgard, S., Treiber, D. K., Gallant, P., Atteridge, C. E., Campbell, B. T., Chan, K. W., Ciceri, P., Davis, M. I., Edeen, P. T., Faraoni, R., Floyd, M., Hunt, J. P., Lockhart, D. J., Milanov, Z. V., Morrison, M. J., Pallares, G., Patel, H. K., Pritchard, S., Wodicka, L. M., and Zarrinkar, P. P. (2008) A quantitative analysis of kinase inhibitor selectivity, Nat. Biotechnol. 26, 127-132. 